\title{
A REPRESENTAÇÃO HISTÓRICA EM DOIS IRMÃOS, DE MILTON
}

HATOUM.

THE HISTORICAL REPRESENTATION IN DOIS IRMÃOS (TWO BROTHERS), BY

MILTON HATOUM.

Katrym Aline Bordinhão dos Santos ${ }^{1}$

\section{Resumo}

Para analisarmos a representação do momento histórico de um período autoritário, no caso a ditadura brasileira, e seus desdobramentos na vida de um personagem romanesco, inicialmente esclareceremos a nossa visão diante da relação estabelecida entre literatura e história. Assim, utilizaremos teóricos como Antoine Compagnon e Frederic Jameson, além de outros que se mostrarem importantes no processo de pesquisa. Em seguida, nosso foco será o personagem Laval, do romance Dois irmãos, de Milton Hatoum, sendo esse livro, portanto, nossa principal fonte de reflexão, haja vista que será a partir da representação realizada por essa fonte que pautaremos as reflexões acerca de um período histórico comumente retratado na literatura, certamente de formas diversas da que é realizada pelo romance em questão. Para tal reflexão, aplicaremos as questões teóricas encontradas na pesquisa bibliográfica acerca do tema nas situações que percebemos envolver a temática histórica dentro do romance Dois irmãos, permitindo, assim, que esclareçamos de que forma o período histórico da ditadura foi representado na obra literária, portanto, ficcional, tendo em pauta a figura do personagem Laval. Nossa metodologia será, então, regida pela pesquisa bibliográfica em ambas as áreas de interesse: história e literatura, e suas possíveis relações.

Palavras-chave: Literatura. Representação. História. Ditadura.

\begin{abstract}
This work has as a purpose to analyze the representation of a historical moment - the Brazilian dictatorship, specifically - and its consequences in the life of a character, we will initially clarify our line by establishing relationship between Literature and History. Thus, we are going to use theorists such as Antoine Compagnon and Frederic Jameson as well as others who have revealed to be important in such research process. Then, we will focus on the character Laval, from the novel Dois irmãos (Two Brothers), by Milton Hatoum. This book is our main object of reflection, since we will use it as a basis to make some considerations - certainly different from what was depicted in the novel - about a historical period commonly evoked in Literature. In order to do that, we will apply the theoretical conceptions from the bibliographical research on the theme in the situations that we notice that involves the historical theme inside the novel. In that way, we will try to clarify in which ways the historical moment in Brazilian dictatorship was represented in the literary - therefore, fictional - work, having at hand the character Laval. As a method, we will undertake bibliographical research in both areas of interest: History, Literature, and their possible relationship.
\end{abstract}

Keywords: Literature. Representation. History. Brazilian dictatorship.

\footnotetext{
${ }^{1}$ Mestre em Estudos Literários pela Universidade Federal do Paraná. Atualmente é doutoranda em Estudos Literários pela Universidade Federal do Paraná (UFPR - CAPES). E-mail: katrymalineb@gmail.com
} 


\section{Introdução}

A literatura e a história são áreas de pesquisa que, comumente, entram em contato, seja com o intuito de explicar uma pela outra ou mesmo por meio da discussão de como podem ser vistas como modos de representação de uma realidade, considerando que seja possível definir esse conceito. $\mathrm{Na}$ história da teoria literária encontramos vertentes de estudos que defendem a ideia de que a história, ou ao menos o contexto histórico em que uma obra literária foi criada, esclarecem o objeto literário, ou a literariedade ${ }^{\mathrm{i}}$ que se pode atribuir a uma obra.

Em O demônio da teoria (2001), Antoine Compagnon registra algumas questões que envolveriam essa relação em capítulo inteiramente dedicado à relação da história com a literatura: "Invocar o contexto histórico serve geralmente, na verdade, para explicar o movimento literário. Trata-se mesmo da explicação mais coerente: a literatura muda porque a história muda em torno dela" (2001, p.194).

Interessados nessa proximidade entre história e literatura, nos propomos a realizar a análise de um personagem do romance Dois irmãos, do escritor manauara Milton Hatoum, que parece desempenhar um papel importante no que se pode considerar como a representação de um fato histórico dentro de uma obra ficcional, no caso, um romance. Tratase, portanto, da representação da situação de um personagem na vivência de um período autoritário.

O personagem em questão é Laval, cuja aparição no romance é rápida, mas de grande influência para a vida de um dos irmãos que dão nome ao livro, Omar. Laval era professor de literatura e a rapidez com que aparece no romance se dá por conta de sua morte, ocorrida após prisão em praça pública, em dias que se seguiram à ocorrência do golpe militar de 1964.

Tendo em vista o romance Dois Irmãos, Tânia Pelegrini observa (2004, p.123):

nessa trama, mais no segundo que no primeiro romance ${ }^{\mathrm{ii}}$, avulta também o tempo da história brasileira, disfarçado como tema secundário: o do processo de modernização do país, com ecos específicos na região norte, que, talvez mais do que em outros lugares, revela com crueza as marcas da convivência de progresso e atraso, de avanço e estagnação, de permanência e mudança. Os dois livros têm Manaus como seu espaço privilegiado, a cidade ilhada pelo rio e pela floresta, que, desde o fim da belle époque da borracha, adaptou-se como foi possível a cada nova circunstância dada pelo desenvolvimento do capitalismo. Nesse sentido, tem-se a história do país refletida num pequeno mundo e a ele circunscrita, transmitindo valores humanos específicos, assim fazendo a passagem do local para o universal. 
Essa abordagem da reflexão de situações político-sociais ocorridas nas regiões consideradas como mais desenvolvidas do país apresenta o retrato de uma Manaus que se vê cercada por soldados e tanques, sendo obrigada a lidar com esse tipo de resistência ao mesmo tempo em que convivia com quedas de energia, que demonstravam os dois lados da modernidade que ali se instalava aos poucos.

Pelegrini destaca que o tema da história brasileira se mostra camuflado, como de segundo plano, o que parece ser justamente o ponto de diferença entre uma narrativa que apresente um fato histórico em seu desenvolvimento e aquela que o toma como ponto principal em seu desenvolvimento, o que poderia ser considerada uma das diferenças que envolvem uma fonte histórica de um romance.

Vê-se, portanto, que há a ligação de um fato dito histórico com a ficção que permeia o romance, o que possibilita a reflexão acerca da representação de um fato histórico na obra literária. Neste trabalho temos por base o que ocorre, especificamente, com o personagem Laval, cujo destaque na narrativa é discreto, mas que, compreendemos revelar um exemplo de abordagem de um fato histórico sem que ele seja o elemento central da narrativa.

\section{Relações entre história e literatura}

Considerando a atualidade e recorrência da discussão que envolve a literatura e a história, que muitas vezes é vista como esclarecedora do processo de organização literária, propomos lançar mais um texto reflexivo acerca dessa relação, tendo em vista a recorrência ${ }^{i i i}$ de representações do período autoritário por nós escolhido, o golpe militar de 1964, na literatura brasileira.

De acordo com Compagnon (2001, p.198): “uma teoria pode recusar a história como quadro explicativo da literatura, mas não pode ignorar que a literatura tem, fatalmente, uma dimensão histórica". Assim, apontamos um primeiro entendimento de nossa visão diante dessa relação entre literatura e história, da qual não acreditamos ser possível nos desviar no momento de analisar uma obra literária.

Uma das polêmicas que envolvem essa relação é a utilização apenas do contexto histórico para a interpretação de uma obra literária. Possivelmente, essa seja a ideia mais comum acerca das presumíveis relações entre literatura e história, já que muitas vezes o contexto histórico é evocado na interpretação de uma obra, como que em um intuito de justificar as escolhas do autor ou do narrador na organização ideológica do texto literário. 
Porém, sabemos que essa relação vai além de uma contextualização, pois a própria conceituação de história e literatura aponta para uma problemática diante do que se assumirá sob tais denominações.

De modo geral, diferencia-se discurso histórico e discurso ficcional por conta da documentação que, em tese, comprovaria a veracidade do que é relatado pela história, ou seja, há uma fonte que comprova a veridicidade do que é representado. Enquanto que a literatura, por sua vez, não precisa de fatos pré-existentes e comprovações, girando em torno de mais possibilidades de criação.

Desse modo, prossegue o teórico: "a hipótese central da história literária é que o escritor e sua obra devem ser compreendidos em sua situação histórica, que a compreensão de um texto pressupõe o conhecimento de seu contexto" (COMPAGNON, 2001, p. 201). É diante dessa observação, portanto, que se apresenta uma das justificativas da escolha do objeto de pesquisa deste trabalho, pois, se considerarmos que é preciso estar ciente do contexto histórico que envolve uma obra, é necessário, então, realizar uma escolha de interpretação de um fato histórico, no caso de nosso interesse, a ditadura brasileira, cuja própria denominação utilizada já esclarece a visão que o interlocutor tem diante do acontecimento.

Sendo utilizado muitas vezes de forma questionável, o trabalho com a contextualização histórica perpassa uma reflexão interpretativa sobre a importância e o efeito criado pelos acontecimentos, que culminaram em uma influência na escrita de determinada obra literária. É, então, um processo que envolve o entendimento do que se pode compreender como história e como literatura, como já mencionado.

Sabendo da importância de se conhecer o contexto histórico vivido pelo escritor no ato da redação de seu romance, tal situação se mostra ainda mais marcante quando o próprio texto aborda um fato histórico, influenciado pela recepção que teve na realidade desse autor e na realidade que pretende representar na obra literária. Fatores como distanciamento temporal e geográfico influenciam no entendimento e representação que se fará do episódio histórico, que não precisa estar ligado à versão oficial que se dá sobre seu desenvolvimento.

A própria questão da admissão da responsabilidade do que está sendo relatado entra em jogo nessa tarefa de representação. Paula Puhl problematiza a questão da responsabilidade de quem narra um texto dito histórico e um visto como ficcional, conforme aponta ao discutir Gérard Genette (PUHL, 2003, p.6): 
relação dos atos realizados à transcrição mecânica das falas pronunciadas. Mas quando se trata de uma narrativa parcial ou completamente fictícia, o trabalho da ficção se exerce igualmente sobre os conteúdos verbais e não verbais, tem por efeito mascarar a diferença que separa os dois tipos de imitação. Um está em frase direta, enquanto o outro faz intervir um sistema mais complexo.

Essa transcrição mecânica supõe uma ideia de fidelidade ao fato ocorrido que ignora que há uma interpretação por detrás disso. Sobre a temática, José Saramago (citado por REIS, 1998, p. 86-87) aponta que:

\begin{abstract}
Evidentemente que aquilo que nos chega não são verdades absolutas, são versões de acontecimentos, mais ou menos autoritárias, mais ou menos respaldadas pelo consenso social ou pelo consenso ideológico ou até por um poder ditatorial que dissesse "há que acreditar nisto, o que aconteceu foi isto e portanto vamos meter isto na cabeça". O que nos estão a dar, repito, é uma versão. [...] Noutros termos: por que é que a literatura não há-de ter também a sua própria versão da História? De qualquer forma, a literatura não é nada que se sobreponha completamente à História, porque não pode, porque tem que alimentar-se até de versões opostas ou contraditórias, assim construindo, à luz de um tempo ou de um entendimento diferente, a sua própria versão.
\end{abstract}

Vemos que Saramago toca em um ponto importante diante da convivência da história e da literatura em uma obra literária, o fato de que elas não precisam, obrigatoriamente, ter algum tipo de relação com a versão oficial de um fato histórico. Justamente o que problematizamos anteriormente e que nos motiva a compreender como a ditadura brasileira se mostra no romance de Milton Hatoum.

A versão da história a que Saramago se refere envolve a questão da verossimilhança literária, pois se há uma abordagem de um acontecimento histórico, que difere da história propriamente, é porque a obra em si mesma se equivale. Em outras palavras, se é criada uma ambientação que sustente a versão ali protagonizada de um fato histórico, mesmo que questione toda uma tradição histórica, a obra é verossímil e, portanto, adaptada ao caráter ficcional que, lembremos, envolve toda obra literária.

Portanto, a representação é o enfoque dessa discussão, que suscita polêmicas, dada a proximidade entre discurso histórico e literário. De acordo com Renata Leite, Szesz e Santana (2010, p. 173): "a partir desse conceito de representação enquanto linguagem, a conclusão é óbvia: o discurso histórico é uma representação ficcional, e a História não seria ciência, mas literatura (esse é o principal argumento dos pós-modernos)". Vê-se, então, que há a admissão do caráter ficcional que envolveria os dois discursos. 
Diante, ainda, da explicação de Saramago o termo romance histórico mostra-se como crucial nessa relação entre a (s) versão (ões) de história que pode(m) ser apresentada(s) na literatura. A denominação tradicional do conceito envolve a figura do teórico George Lukács (1981), que em sua obra, O romance histórico, propôs como premissas desse tipo de romance a existência de personagens históricos no enredo, e sua convivência com os personagens ficcionais, além das descrições de mudanças que envolvem a sociedade ali retratada.

Tem-se, portanto, o conceito tradicional desse tipo de romance, que é questionado diante das tendências modernas desse modo de abordagem no âmbito ficcional, como defende Frederic Jameson (2007, p.187): "Não seria o caso de que tais romances históricos modernistas, como se pode argumentar, se mostrariam relativamente indistinguíveis de outras obras modernistas não-históricas?”.

A professora Marilene Weinhardt em capítulo intitulado "Romance histórico: das origens escocesas ao Brasil finissecular", constante no livro Ficção histórica: teoria e crítica (2011), menciona diversos teóricos ${ }^{\text {iv }}$ que têm se ocupado da questão nos últimos anos, segundo ela:

\footnotetext{
Vale ainda lembrar que a possibilidade de classificar um texto como romance histórico tradicional ou novo romance histórico, com maiúsculas ou não, não é critério de avaliação estética, mas indicação dos recursos narrativos, independente do sucesso ou do fracasso dos efeitos alcançados. (WEINHARDT, 2011, p.49).
}

Assim, após discussões acerca dessa polêmica convencionou-se uma nova caracterização para o romance histórico, dito como contemporâneo, e que tem como um exemplo representativo a obra Memorial do Convento, de José Saramago. Isso se dá por conta da utilização, nessa obra e nas demais produções contemporâneas, de uma linguagem anacrônica por parte do narrador, intertextualidade, uso de ironia e paródia, a presença da metalinguagem, que colabora para a reflexão do ato da realização artística, e a distorção consciente de questões históricas. Tais especificidades foram estabelecidas por conta dos trabalhos de Fernando Ainda (1991) e Seymor Menton (1993).

Marilene Weinhardt ainda aponta que "Noé Jitrik [...] destaca alguns comportamentos da ficção contemporânea que classifica como intraliterárias: a proliferação das possibilidades narrativas; a penetração da linguagem da poesia na narrativa; a derrocada dos conceitos tradicionais de verossimilhança e de linearidade.” (2011, p.42), apresentando mais marcas que envolveriam a contemporânea produção histórica. 
Diante de tais constatações, passemos à análise de Dois irmãos, de Milton Hatoum, buscando refletir sobre tais definições de romance histórico e a representação realizada do período histórico da ditadura.

\section{A representação histórica em Dois Irmãos}

Dois irmãos apresenta a vida de irmãos gêmeos, Omar e Yaqub, que se desentendem durante toda a vida, o que os leva para caminhos totalmente diferentes, causando desdobramentos na rotina de toda a família e das pessoas que os cercam. A relação entre os irmãos e as mulheres da casa, mãe, irmã e empregada, é cercada de insinuações, tanto por conta da preferência da mãe por um dos meninos, o comportamento da irmã diante dos irmãos e os relatos da empregada sobre a convivência com eles.

O narrador do romance, Nael, é o filho não assumido de um dos gêmeos com a empregada da casa. A paternidade não é esclarecida, e na tentativa de elucidar pontos importantes para a organização das informações de que dispõe, o narrador passa a contar a história da família, dando ênfase às situações que envolvem os gêmeos.

Um desses irmãos, Omar, tem na figura de um antigo professor, Laval, um grande companheiro, sendo que essa amizade é um dos únicos fatores responsáveis pela atribuição de uma sensibilidade ao personagem, que, na maior parte do romance, é retratado negativamente. O professor, que lecionava língua francesa e literatura, é apresentado também como poeta e, repentinamente, demonstra comportamentos inesperados:

\footnotetext{
Depois, em março, ele faltou às primeiras aulas e só apareceu na terceira semana do mês. Entrou na sala com uma expressão mais abatida do que quando o vira em casa, o paletó branco cheio de nódoas, os dedos da mão esquerda e os dentes amarelados de tanto fumar. "Desculpem-me, estou muito indisposto", disse em francês. "Aliás, muita gente está indisposta", murmurou agora em português. (HATOUM, 2000, p. 141).
}

Parece-nos que a inserção discreta da ocorrência dessa indisposição geral é uma das primeiras referências que o romance faz ao período da ditadura, haja vista que o narrador esclarece a data do ocorrido: "O professor de francês não voltou mais ao liceu, até que numa manhã de abril nós presenciamos sua prisão" (HATOUM, 2000, p. 142). Compreende-se que o uso desse vocábulo já demonstra a opinião desse narrador diante do período. Para Daniela 
Birman essas opiniões divergentes, inclusive, permeiam a relação entre os irmãos gêmeos que dão nome ao livro:

\begin{abstract}
Ao entrelaçar a trama de ódio entre os gêmeos Yaqub e Omar ao relato deste acontecimento histórico, o narrador do romance também revela-nos a permanência de um fundo de semelhança sobre o qual se atrita uma feroz oposição. Pois, na medida em que avança no enredo da discórdia entre os irmãos, ele nos mostra como os dois, indivíduos de temperamento, ambição e comportamento extremamente contrastantes, manifestam-se similares. E esta semelhança não se traduz num mesmo posicionamento em relação à ditadura militar. É, pois, na sua diferença que eles se revelam fortemente parecidos, de modo próximo, aliás, ao dos gêmeos de Machado. (BIRMAN, 2008, p.7).
\end{abstract}

Esse posicionamento diante do momento histórico vivido vai se mostrar mais no período adulto dos irmãos, que podem alegorizar, diante dos rumos de vida tomados, como um mesmo evento pode ser interpretado diferentemente, o que nos encaminha à discussão feita sobre a representação de um fato histórico.

Como já mencionado, a aparição do personagem Laval é relativamente rápida durante o decorrer do romance, pois apenas em algumas páginas somos apresentados aos seus hábitos, prisão e, por fim, ao seu destino depois de dias preso:

Foi humilhado no centro da praça das Acácias, esbofeteado como se fosse um cão vadio à mercê da sanha de uma gangue feroz. Seu paletó branco explodiu de vermelho e ele rodopiou no centro do coreto, as mãos cegas procurando um apoio, o rosto inchado voltado para o sol, o corpo girando sem rumo, cambaleando, tropeçando nos degraus da escada até tombar na beira do lago da praça. Os pássaros, os jaburus e as seriemas fugiram. A vaia e os protestos de estudantes e professores do liceu não intimidaram os policiais. Laval foi arrastado para um veículo do Exército, e logo as portas do Café Mocambo foram fechadas. Muitas portas foram fechadas quando dois dias depois soubemos que Antenor Laval estava morto. Tudo isso em abril, nos primeiros dias de abril. (HATOUM, 2000, p. 142).

A descrição minuciosa, e com destaque à violência dos atos cometidos contra o professor - "esbofeteado como se fosse um cão vadio à mercê da sanha de uma gangue feroz" (HATOUM, 2000, p. 142) - apontam a visão que será repassada do que o momento histórico significou para quem representasse qualquer tipo de ameaça diante daquela ocasião que começava a se desenvolver, como o próprio narrador comenta ao fim do trecho supracitado.

O descontentamento, representado pelas vaias e protestos dos colegas de Laval, também demonstra a contrariedade à ação desempenhada, exemplificando um comportamento adverso às atitudes tomadas pelos policiais. Nesse momento da narrativa, o leitor pode ainda 
não entender o porquê dessa ação, que pode ser compreendida como uma alegorização das conhecidas prisões e contestações do período.

No decorrer do enredo, porém, esclarece-se um possível motivo para a prisão e morte do professor:

Porque de sua vida ninguém tinha notícias claras: um caracolzinho entre pedregulhos. Só um zunzum corria nos corredores do liceu, dois dedos de mexerico da vida alheia, dele, Laval. Um: que fora militante vermelho, dos mais afoitos, chefe dos chefes, com passagem por Moscou. Ele não negava, tampouco aprovava. (HATOUM, 2000, p. 144).

A relação com a política, portanto, foi a motivação para a captura de Laval, que costumava abordar o tema, mesmo que o evitasse em sala de aula: "detestava pompa, ria dos políticos da província, espicaçava-os durantes os intervalos, mas recusava-se a falar sobre o assunto no meio de uma aula. Dizia: 'Política é conversa de recreio. Aqui na sala, o tema é muito mais elevado. Voltemos à nossa outra noite... "” (HATOUM, 2000, p. 143).

Dessa forma compreendemos como a representação da história abarca a visão assumida pelo narrador e os fatores fictícios nela envolvidos. O narrador, Nael, também admirava esse professor, não encontrando motivos para tamanho ato de violência contra ele, o que pode justificar sua narração dramática do fato ocorrido, encaminhando o leitor para uma interpretação que induz situações pessoais e questionando os desdobramentos históricos que podem ter levado a essa prisão.

A cidade de Manaus, como um todo, passava por mudanças advindas dos surtos de modernidade que invadiam o país. De acordo com Tânia Pelegrini (2004, p. 131):

\footnotetext{
Mais tarde, chegam a Manaus também os ecos da euforia da inauguração de Brasília, denunciando outras ideologias, a da integração nacional juscelinista e do discurso "modernizador" do regime militar. Nessa transculturação problemática, são os dois brasis que se defrontam - o mormaço e o atraso do norte, o frio e o progresso do sul - numa praça de Manaus, onde a crueldade da repressão mata o professor de francês Antenor Laval.
}

É no relato desses momentos e contrastes, conforme pontuado pela estudiosa, que o autor organiza a relação desempenhada entre a representação fictícia de fatos históricos que envolvem a narrativa. Partindo da problematização da instauração do regime militar, somos apresentados a diversas situações com as quais a população teve de lidar, o que pode constituir um relato baseado em fontes, marcado pelo caráter histórico, mas também pela representação de uma experiência pessoal, passível de fíccionalização, uma vez que 
é importante lembrar que na literatura de inspiração histórica, os autores podem utilizar livremente os fatos da história, desde que não os desconstruam a ponto de torná-los irreconhecíveis aos leitores. Os fatos não são mais história, são constituintes de um enredo fictício e podem ser alterados na medida em que o futuro dos personagens fictícios toma seu rumo. (SOISTAK; OLIVEIRA, 2010, p. 67)

Isso reitera, portanto, a relação de total liberdade que a literatura tem diante da representação de um fato histórico. Essa situação nos remete à problemática de se considerar uma obra literária como fonte histórica principal na pesquisa sobre determinado período histórico. Por outro lado, é absolutamente possível considerá-la como colaboradora nesse processo de investigação, haja vista a representação que é realizada diante dos desdobramentos causados pelo fato histórico. Vejamos, por exemplo, como Dois irmãos retrata as mudanças ocorridas na cidade de Manaus durante o período do regime militar:

\begin{abstract}
Ele sabia que Manaus se tornara uma cidade ocupada. As escolas e os cinemas tinham sido fechados, lanchas da Marinha patrulhavam a baía do Negro, e as estações de rádio transmitiam comunicados do Comando Militar da Amazônia. Rânia teve que fechar a loja porque a greve dos portuários terminara num confronto com a polícia do Exército. Halim me aconselhou a não mencionar o nome de Laval fora de casa. Outros nomes foram emudecidos. (HATOUM, 2000, p. 149)
\end{abstract}

A alteração da rotina da família aparece como uma metonímia para o que toda a cidade vinha enfrentando, o que fez com que se criassem mecanismos de defesa entre os moradores. Atente-se para a orientação do patriarca da família para a omissão do nome de Laval, que poderia gerar consequências similares a que ele foi vítima. Temendo as decorrências do fato, Rânia fecha o comércio da família, diante dos entraves entre grevistas e polícia. Dessa forma, tais relatos constituem

\footnotetext{
Um retrato fidedigno dos anos de chumbo. Não é mera coincidência a abordagem deste período de trevas. A questão identitária da nacionalidade tupiniquim perpassa, obrigatoriamente, pela autonomia do indivíduo, sua cidadania e criticidade reflexiva, construída dentro dos parâmetros da similitude e distinções de suas escolhas pessoais e sociais. (MENEZES, 2009, p.3)
}

Consideramos que é justamente a questão das escolhas pessoais e sociais, mencionada por Menezes (2009), a representação, em Dois irmãos, de uma alegoria da relação entre história e literatura. Afinal, é por meio da ficcionalização da história de irmãos, contrários à ditadura, que temos acesso a um fato histórico cujo alcance envolveu todo o país, assim, "o assassinato do professor metaforiza o sangue jorrado em praça pública, encarcerando a liberdade de expressão e inibindo manifestações de cunho político. É a sede vampiresca dos 
parvos pelo poder, esmagando toda exteriorização de vida inteligente que encontra pelo caminho" (MENEZES, 2009, p.4).

O professor, portanto, apresenta uma consequência do episódio histórico autoritário ali apresentado, representando um desdobramento ficcional advindo de um fato histórico, o que se identifica com uma das premissas do romance histórico tradicional proposto por Lukács (1991), conforme já mencionado. É preciso esclarecer, porém, que o fato histórico não é o fio que conduz a narrativa de Hatoum. Ao mesmo tempo, verificamos como há aproximação com tendências do romance histórico contemporâneo por conta da alegorização da relação entre ficção e história.

\section{Conclusão}

O período de ditadura militar no Brasil evoca diversas representações ficcionais. Ao se referenciar a esta representação, o autor assume que

\footnotetext{
precisa de uma dose muito maior de criatividade para chamar a atenção dos leitores sobre algo que eles já conhecem, ou seja, não basta apenas que o autor do romance insira em sua trama um conjunto de acontecimentos para que o romance corresponda à expectativa de seus leitores. Ele precisa reformular, dar uma nova roupagem aos fatos selecionados e provocar uma reflexão no leitor. (SOISTAK; OLIVEIRA, 2010, p.70)
}

Mesmo que a questão da ditadura não seja o fio condutor do enredo, tendo maior destaque na representação do personagem professor Laval, o assunto é retratado de forma análoga à ideia de romance histórico contemporâneo, considerando a conclusão de Jameson sobre o assunto:

\footnotetext{
Parece-me que é a forma narrativa desse evento primordial ou axial que deve estar presente, ou ser recriada, no romance histórico para que ele se torne histórico no sentido genérico. Ademais, dadas as restrições e os limites da representação narrativa, esse evento terá de figurar mais na qualidade de uma irrupção coletiva que de data de nascimento de algo como um movimento religioso ou político: deve, de algum modo, estar presente em carne e osso, e pela multiplicidade mesma de seus participantes representar alegoricamente aquilo que transcende a existência individual. (JAMESON, 2007, p.191)
}

Assim, compreendemos que a representação do momento histórico da ditadura, por meio da figura do personagem professor Laval contribuiu para esse caráter de irrupção coletiva, mencionado por Jameson, na medida em que serve como mote para discussões de 
outros personagens sobre o momento vivenciado, figurando, desse modo, como uma espécie de atualização de uma das tendências do romance histórico, a descrição das mudanças difundidas por conta do episódio histórico retratado.

A intenção neste texto, por fim, não foi a denominação de Dois irmãos como um romance histórico, mas sim a de verificar de que forma é possível problematizar a representação histórica em uma obra de ficção, o que se mostrou profícuo, tendo em vista que o episódio autoritário retratado na obra trouxe à tona a concepção de literatura, história, alegoria social e fontes históricas.

\section{Notas}

\footnotetext{
i "A literariedade de um texto, lembremo-nos, se caracteriza por um deslocamento, uma perturbação dos automatismos da percepção" (COMPAGNON, 2001, p. 208).

ii Tânia Pelegrini se refere ao primeiro romance de Milton Hatoum, Relato de um certo Oriente, lançado em 1989.

iii O próprio Milton Hatoum aborda o tema novamente no romance Cinzas do Norte, em 2005.

iv A professora menciona, entre outros, os estudos de Fernando Ainsa (1991), Seymor Menton (1993) e Antonio Roberto Esteves (2010), essenciais para a compreensão do percurso teórico que envolve a denominação de novo romance histórico.
}

\section{Referências}

AINSA, Fernando. La nueva novela histórica latinoamericana. Plural, 240, 1991, p. 82-85.

BIRMAN, Daniela. Irmãos inimigos: duplos em Machado e Hatoum. In: I SEMINÁRIO MACHADO DE ASSIS, 2008, Rio de Janeiro. Anais... Disponível em: $<$ http://www.filologia.org.br/machado_de_assis/Irm\%C3\%A3os\%20inimigos\%20duplos\%20em\%20Machado\%20e\%20Hatoum.pdf> Acesso em: 20 mar. 2011.

COMPAGNON, Antoine. O demônio da teoria: literatura e senso comum. Tradução: Cleonice Paes Barreto Mourão, Consuelo Fortes Santiago. Belo Horizonte: UFMG, 2001.

ESTEVES, Antonio R. O novo romance histórico brasileiro contemporâneo (1975-2000). São Paulo: Ed. UNESP, 2010.

HATOUM, Milton. Dois irmãos. São Paulo: Companhia das Letras, 2006.

JAMESON, Frederic. O romance histórico ainda é possível? In: Novos Estudos. São Paulo, n.77, p. 185-203, mar. 2007. Disponível em: < http://www.scielo.br/pdf/nec/n77/a09n77.pdf $>$. Acesso em 03 out. 2013.

LEITE, Renato Lopes; SZEZS, Christiane Marques; SANTANA, Camila Jansen de Melo de;. Cultura política: imaginário e representações. In: ESPECIALIZAÇÃO EM HISTÓRIA, ARTE E CULTURA: LIVRO 3, por Rosângela Wosiack Zulian e outros. Ponta Grossa: UEPG/NUTEAD, 2010.

LUKÁCS, George. The Historical Novel. New York: Penguin Books, 1981. 
MENEZES, Denilson Costa. RESENHA: Dois irmãos, de Milton Hatoum. In: Revista Eletrônica - Cadernos Da Fael. Nova Iguaçú, v.2, n. 6, set./dez. de 2009. Disponível em: $<$ http://www.unig.br/cadernosdafael/voll_num3/RESENHA\%20DENILSON.pdf $>$. Acesso em 03 out. 2013.

PELEGRINI, Tânia. Milton Hatoum e o regionalismo revisitado. Luso-Brazilian Review, Volume 41, Number 1, 2004, pp. 121-138. Disponível em:

http://muse.jhu.edu/journals/lbr/summary/v041/41.1pellegrini01.html. Acesso em 03 out. 2013.

MENTON, Seymour. La nueva novela histórica de la América Latina: 1979-1992. México: Fondo de Cultura Económica, 1993.

PUHL, Paula. Análise da narrativa no caso: Agosto. Biblioteca on-line de Ciências da Comunicação. Disponível em: http://bocc.ubi.pt/ esp/autor.php?codautor=770. Acesso em: 03 out. 2013.

REIS, Carlos. Diálogos com Saramago. Lisboa: Caminho, 1998.

SOISTAK, Angelis.; OLIVEIRA, Silvana. Literatura e história: ficção e discurso histórico em José Saramago. In: ESPECIALIZAÇÃO EM HISTÓRIA, ARTE E CULTURA: LIVRO 3, por Rosângela Wosiack Zulian e outros. Ponta Grossa: UEPG/NUTEAD, 2010.

WEINHARDT, Marilene. Romance histórico: das origens escocesas ao Brasil finissecular. In: (org.) Ficção histórica: teoria e crítica. Ponta Grossa: EDITORA DA UEPG, 2011. 